\title{
The perception of gonna and gotta - a study of emancipation in progress
}

David Lorenz

Albert-Ludwigs-Universität Freiburg

https://doi.org/10.36505/ExLing-2012/05/0020/000226

\begin{abstract}
This is an experiment the perceptual differences between full and contracted semi-modals in English, i.e. the distinction of going to vs gonna and (HAVE) got to vs gotta. It is a listen-and-repeat experiment and is informed by the findings of a corpus study of the use of these forms in American English (AmE). It thus aims to integrate the social/variational and the cognitive sides of the phenomenon.
\end{abstract}

Key words: word perception, language change, modality, English

\section{Introduction}

The contraction of the English semi-modals BE going to and HAVE got to to gonna and gotta is well known (Pullum 1997, Krug 2000). The hypothesis here is that this contraction is in the process of change from phonological to lexical variation, that is, the contracted forms are developing from pronunciation variants to independent items. This process, which I have called 'emancipation', has been shown in usage through corpus studies of American English (Lorenz forthc.).

The study presented here aims to test this on perception by applying some of the factors shown to have an effect on usage to a listen-andrepeat experiment. The experiment elucidates what conditions lead listeners to recognize a contraction (or not), and to what extent they accept gonna and gotta as words in their own right.

\section{Experiment design}

Participants listened to recorded sentences containing one of four possible realizations of going to/gonna, or one of four realizations of (HAVE) got to/gotta. The variants included can be represented as:

"going to" - "goinde" - "gonna" - "ena"

"ve got to" - "got to" - " "ve gotta" - "gotta"

On these target forms, three test conditions were stipulated based on corpus results, and contrasted with a null condition:

-Subject: In corpus studies, 1st person singular favors phonetic reduction of going to/gonna; 3rd person singular favors HAVE got to.

(1) After dinner, I'm going to/gonna play backgammon with the camel.

(2) Our African giraffe (has) got to/gotta see a dentist.

ExLing 2012: Proceedings of 5th Tutorial and Research Workshop on Experimental Linguistics, 27-29 August 2012, Athens, Greece 
- Type of modality: In corpus studies, 'deontic' favors going to; 'epistemic' favors (HAVE) got to/gotta over HAVE to.

(3) Listen, you're going to/gonna leave that giraffe alone now.

(4) Surely, they ('ve) got to/gotta have elephant food at the pet shop.

- Speech rate: In corpus studies, high speech rate promotes reduction. The sentence speech rate was enhanced from 5-6 syllables/second to 7-8 syll/s; at the target form, the tempo was increased by $40 \%$.

- The null condition is neutral with respect to all of these.

(5) So now I ('ve) got to/gotta run over there to pick up the crocodile.

(6) The penguins are going to/gonna form a Blues quartet.

Participants were asked to repeat these sentences clearly and literally (i.e. the "words" they heard). Thus, their output reveals whether the form was perceived as an instance of going to or gonna, or of got to or gotta, and the resulting preference patterns show the conditions' effects on the perception of the input forms.

The input sets were designed so that a participant would encounter each variant in a given condition four times (but not every condition was present in every set). About half of the input sentences did not contain a target form. The stimuli were played in random order.

The fifty-nine participants are native speakers of North American English (mostly Canadians). Their age and sex are taken into account.

\section{Results}

The data for each input variant were statistically assessed using mixedeffects regression models (Baayen 2008, Bates 2005). The individual participant, the order of the stimuli, and the specific input sentence are controlled for by random factors.

\section{Results for going to/gonna}

Overall, gonna was the preferred output variant (which corresponds to its preference in usage). Even the full input "going to" was returned as gonna at 48\% ("goinde": 59\%, "gonna": 74\%, "ena": 75\%).

A general effect was found for the participant's age: younger subjects responded with gonna more often, irrespective of the input form (though statistical significance varies, see Fig.1).

Fig.2 presents the output patterns for the two conditions that favor phonetic reduction in speech. Increased speech rate has an effect only on input "goinde", prompting its perception as gonna ( $\mathrm{p}=.001)$. By contrast, a first person singular subject leads to the interpretation of "gonna" and "ena" as going to (as compared to the null condition, $\mathrm{p}=.012$ and $\mathrm{p}=.061$ ). Deontic modality showed no significant effects. 


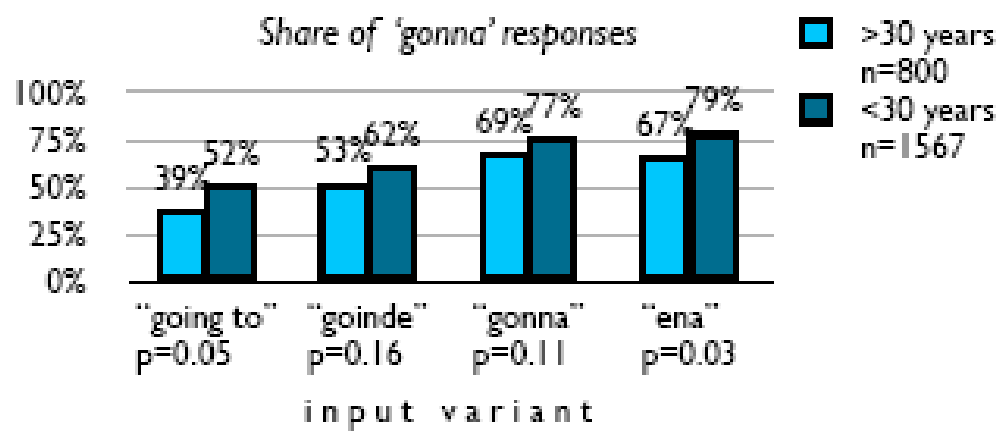

Figure 1: Share of gonna responses by age.

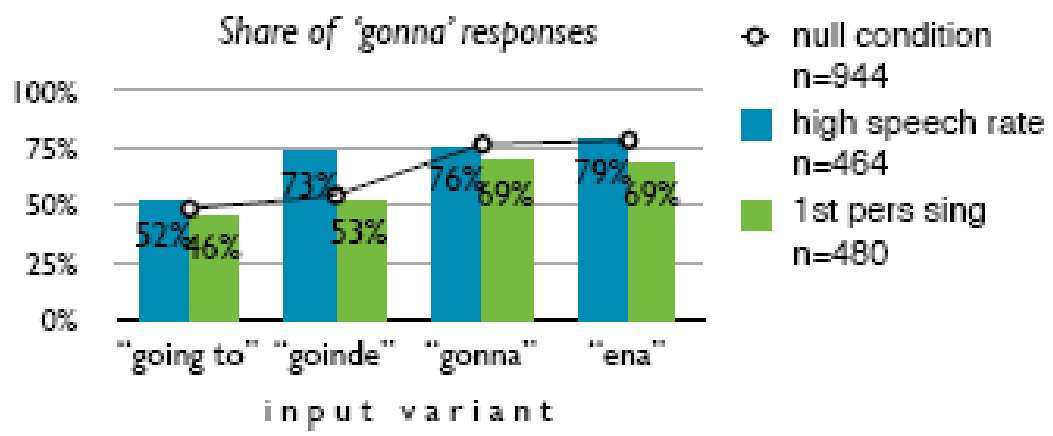

Figure 2: gonna-responses in speech rate and subject conditions.

\section{Results for got to/gotta}

I will focus here on the distinction between got to and gotta, disregarding auxiliary HAVE.

. null condition
$\mathrm{n}=944$
high sp. rate
$\mathrm{n}=480$
epistemic
$\mathrm{n}=464$

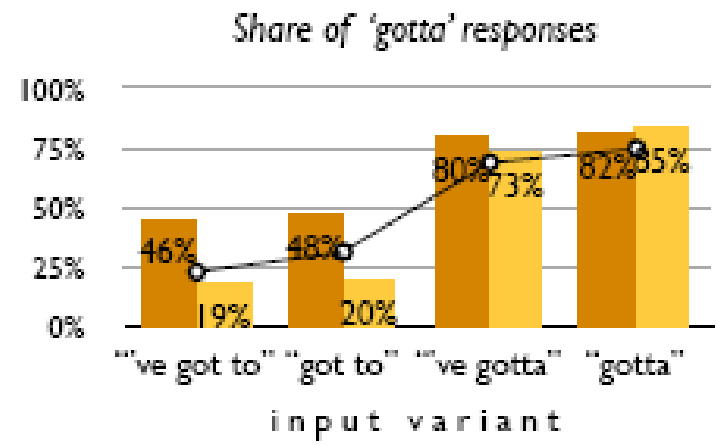

Figure 3: gotta-responses in speech rate and modality conditions. 
A clear effect is found for increased speech rate, favoring perception as gotta of all input variants ( $\mathrm{p}=.011$ overall). Epistemic modality shows significant effects for inputs without HAVE $(\mathrm{p}=.037$ and $\mathrm{p}=.069)$, which are repeated more accurately than in the null condition. (It also elicits more accuracy with respect to auxiliary HAVE.) Third person singular subjects, age and sex have no relevant effects.

\section{Discussion}

The results show that, by and large, language users recognize the contractions and distinguish them from the respective full forms.

The age trend for gonna but not gotta confirms a corpus finding that gonna is on the rise while got to/gotta are losing ground to HAVE to in AmE. Also, corpus data show that gotta is more dependent on speech rate than gonna in speech. This finding extends to perception, showing that gotta is more phonetically conditioned (i.e. less emancipated) than gonna.

Epistemic got to/gotta was repeated more accurately, and in this use the competing HAVE to is not the dominant variant, suggesting a less constrained variation and a possible semantic niche for gotta in epistemic modality.

The factors favoring reduction in speech show a striking difference in perception: Listeners infer reduction, even falsely, from rapid speech ("goinde" as gonna, "got to" as gotta), but reconstruct the full form from a reduced high-frequency collocation ("I'mna" as going to). It seems that in frequent contexts, reduction is expected and hence (hyper-)corrected, while listeners take at face value what they (mis-)hear in rapid speech.

\section{Acknowledgements}

I am indebted to Dr Alex D'Arcy for her great support in conducting this experiment at the University of Victoria; and to the German Research Foundation for funding my research.

\section{References}

Baayen, R.H. 2008. Analyzing Linguistic Data. Cambridge University Press. Bates, Douglas. 2005. Fitting linear mixed models in R. R News 5/1. 27-30.

Krug, Manfred G. 2000. Emerging English Modals. Berlin: de Gruyter.

Lorenz, David. From Reduction to Emancipation: Is gonna a word? To appear in: Hasselgård, H. and Ebeling, J. (eds.), Corpus Perspectives on Patterns of Lexis. Amsterdam: John Benjamins.

Pullum, Geoffrey K. 1997. The morpholexical nature of English to contraction. Language 73. 79-102. 